\title{
Pathway-specific apoptotic gene expression profiling in chronic lymphocytic leukemia and follicular lymphoma
}

\author{
David Hui ${ }^{1}$, Natasha Satkunam², Moayad Al Kaptan², Tony Reiman ${ }^{1}$ and Raymond Lai ${ }^{2}$ \\ ${ }^{1}$ Department of Medicine, Faculty of Medicine and Dentistry, University of Alberta, Edmonton, AL, Canada \\ and ${ }^{2}$ Department of Laboratory Medicine and Pathology, Faculty of Medicine and Dentistry, University of \\ Alberta, Edmonton, AL, Canada
}

\begin{abstract}
Defects in the apoptotic pathway are pathogenetically important in chronic lymphocytic leukemia and follicular lymphoma. To further understand these defects, we profiled the apoptotic gene expression of these two neoplasms. Oligonucleotide arrays with 112 apoptotic genes were used, and data analysis was performed on seven chronic lymphocytic leukemia and 10 follicular lymphoma frozen tumor samples from six and seven patients, respectively. The overall gene expression pattern was strikingly similar among all 17 samples, regardless of the type of lymphoma and history of chemotherapy exposure. MCL1, TNFRSF1B and TNFRSF7 were highly expressed in most cases. The apoptotic gene expression between the groups of untreated chronic lymphocytic leukemia $(n=3)$ and untreated follicular lymphoma $(n=6)$ was also similar (Pearson correlation coefficient, 0.94). Comparison between the groups of untreated chronic lymphocytic leukemia $(n=3)$ and postchemotherapy chronic lymphocytic leukemia $(n=4)$ revealed six genes with $>2$-fold changes, including BIRC5/Survivin that was higher in the postchemotherapy samples. This finding was validated by immunohistochemistry. Similar analysis of follicular lymphoma cases did not identify any significant differences. To conclude, our findings suggest that chronic lymphocytic leukemia and follicular lymphoma share common apoptotic defects, and highlight the importance of $M C L 1$ and the TNF pathway. Upregulation of survivin may be one of the mechanisms by which chronic lymphocytic leukemia becomes desensitized to chemotherapy. Modern Pathology (2006) 19, 1192-1202. doi:10.1038/modpathol.3800632; published online 9 June 2006
\end{abstract}

Keywords: apoptosis; oligonucleotide microarray; chronic lymphocytic leukemia; follicular lymphoma; treatment

Chronic lymphocytic leukemia and follicular lymphoma are the two most common indolent B cell lymphomas in the Western world. ${ }^{1,2}$ Both of these diseases are characterized by a slow and progressive clinical course. With the exception of very early stage disease, relapse is the rule. The median survival for both chronic lymphocytic leukemia and follicular lymphoma is between 7-12 years. ${ }^{1,3,4}$ Despite recent developments in various biological therapies, these tumors remain largely incurable. ${ }^{5,6}$

The pathogenesis of both chronic lymphocytic leukemia and follicular lymphoma is incompletely understood, but multiple defects in the apoptotic pathway have been identified. In follicular

Correspondence: Dr R Lai, MD, PhD, Department of Laboratory Medicine and Pathology, Faculty of Medicine and Dentistry, University of Alberta and Cross Cancer Institute, 4B1 Walter MacKenzie Health Sciences Center, 8440-112 Street, Edmonton, AL, Canada T6G 2B7.

E-mail: Raymondmail_65@yahoo.com

Received 6 March 2006; revised and accepted 20 April 2006; published online 9 June 2006 lymphoma, overexpression of $B C L 2$ as a result of the $t(14 ; 18)$ cytogenetic abnormality is one of the best characterized mechanisms by which apoptosis is inhibited in follicular lymphoma. ${ }^{7}$ However, BCL2 overexpression is not sufficient for lymphomagenesis; ${ }^{8}$ additional defects in the apoptotic pathway appear to be important. Using cDNA microarrays and six tumor samples harvested from relapsed follicular lymphoma patients who had not received chemotherapy 6 months before the biopsy, Husson et a $1^{9}$ reported the differential expression of a number of apoptotic genes in follicular lymphoma compared to benign germinal center $\mathrm{B}$ cells, with a higher expression of BCL2 and TNF and a lower expression of BIK and CASP4 in the follicular lymphoma samples.

Although most cases of chronic lymphocytic leukemia do not have the $\mathrm{t}(14 ; 18)$ abnormality, $B C L 2$ is highly expressed in most cases. ${ }^{10}$ Other alterations of the apoptotic pathway are also believed to contribute to its pathogenesis. ${ }^{10} \mathrm{~A}$ recent meta-analysis of three microarray studies ${ }^{11,12}$ examined the differences in gene expression between chronic lymphocytic leukemia and benign B cells. It 
was found that TNFRSF7, TNFRSF1B and BCL2 were overexpressed, while BCL2A1 and TNF were underexpressed in chronic lymphocytic leukemia. Of note, these three studies included in the meta-analysis employed randomly chosen chronic lymphocytic leukemia cases with varying proportions of treated and untreated tumors. Another study also using randomly chosen chronic lymphocytic leukemia tumor samples showed that BCL2 was the only apoptotic gene with a $>4$-fold difference between reactive lymph node and chronic lymphocytic leukemia. ${ }^{13}$ This same study also included a direct comparison of apoptotic gene expression between chronic lymphocytic leukemia and follicular lymphoma; one proapoptotic gene (IL24) was differentially ( $>4$-fold) expressed between these two diseases.

It is well recognized that tumors previously treated with chemotherapeutic agents are likely to become resistant to subsequent treatments. Correlating with this clinical phenomenon, there is evidence that chemotherapeutic agents can induce changes in apoptotic gene expression, which may be responsible for the increased resistance to chemotherapy. In one study, the levels of a number of soluble tumor necrosis factor (TNF) superfamily proteins were examined in the serum of chronic lymphocytic leukemia patients collected before and after chemotherapy, and significant alterations in the levels of these serum proteins were identified. ${ }^{14}$ Thus, in addition to their roles of promoting lymphomagenesis, modulations of apoptotic gene expression may be implicated in the desensitization to chemotherapeutic agents. Nevertheless, characterization of these changes have not been extensively performed.

In this study, we aimed to further elucidate the apoptotic pathway defects in chronic lymphocytic leukemia and follicular lymphoma. To achieve this goal, we determined the apoptotic gene expression profile of these two lymphomas. In contrast to most of the previous studies that generally analyzed a mixture of previously untreated and treated cases, we utilized only previously untreated chronic lymphocytic leukemia and follicular lymphoma tumor samples for a direct comparison in order to avoid any potential confounding effects related to the exposure of chemotherapy. Additionally, instead of using large-scale cDNA microarrays for which data analysis could be complicated, we employed pathway-specific oligonucleotide arrays that contain 112 apoptotic genes. To assess changes in apoptotic gene expression that may be responsible for desensitization to chemotherapy, we compared results between lymphoma samples with and without prior exposure to chemotherapy.

\section{Materials and methods}

\section{Patients and Tissues Samples}

All cases of chronic lymphocytic leukemia and follicular lymphoma initially diagnosed at the Cross
Cancer Institute between 1998 and 2005 were searched for the presence of multiple frozen tissue biopsy samples in our tumor bank. The use of clinical samples and patient information has been approved by the institution's ethics review board. Only those with sufficient tissues were included in this study. The diagnoses for all cases were confirmed according to the World Health Organization Classification scheme. Based on these criteria, we initially identified six chronic lymphocytic leukemia patients and seven follicular lymphoma patients with sequential frozen tumor samples. Information regarding initial diagnosis, pathology, clinical staging, and treatment were collected retrospectively and summarized in Table 1 .

\section{Oligonucleotide Microarray Analysis}

Total RNA was isolated from frozen tissues using the Qiagen RNeasy mini-column kit. Biotin-UTPlabeled cRNA probe was synthesized using $3 \mu \mathrm{g}$ of purified total RNA and reverse transcriptase (Superarray Inc., Frederick, MD, USA). Purified cRNA $(6 \mu \mathrm{g})$ from each sample was then incubated with an Oligo GEArray ${ }^{\circledR}$ Human Apoptosis Microarray (OHS-012, Superarray Inc.) consisting of 112 genes involved in apoptosis. The hybridized arrays were washed and detected with chemiluminescence according to the manufacturer's instructions. Signals were captured on film and scanned at 300 DPI in the TIFF format. The scanned images were then analyzed by the GEArray analysis suite (Superarray Inc.). Standardization of all the signals was performed by normalizing the raw data with those of $\beta 2$-microglobulin and heat shock 90 protein $1 \beta$. The expression levels of these housekeeping genes were set as 1.0, and all the other genes on the same array were assigned an adjusted score between 0 and 1.0.

\section{Data Analysis}

For the purpose of this study, comparison of gene expression between two groups was focused on those genes in which at least one of the two results was $>0.2$ in the adjusted score. Additionally, only a differential gene expression of $>2$-fold was considered significant. Details of various comparisons of gene expression between different groups are described in the Results section.

\section{Immunohistochemical Staining for Survivin in Chronic Lymphocytic Leukemia}

Ten untreated and nine treated chronic lymphocytic leukemia paraffin-embedded tissue specimens were immunostained with an antisurvivin antibody to determine the protein expression level of survivin. These samples were randomly chosen and were derived from patients different from those included in the oligonucleotide microarray studies. Chemotherapy used for the 10 patients who had been 
Table 1 Clinical information on chronic lymphocytic leukemia and follicular lymphoma frozen tissue samples for microarray analysis (a) Chronic lymphocytic leukemia cases

\begin{tabular}{|c|c|c|c|c|c|c|c|}
\hline Patient & Gender & $\begin{array}{c}\text { Age at } \\
\text { diagnosis }\end{array}$ & $\begin{array}{l}\text { Rai } \\
\text { stage }\end{array}$ & $\begin{array}{l}\text { Sample } \\
\text { label }\end{array}$ & $\begin{array}{l}\text { Year of } \\
\text { biopsy }\end{array}$ & $\begin{array}{l}\text { Treatment(s) } \\
\text { before biopsy }\end{array}$ & Oligonucleotide microarray analysis \\
\hline \multirow[t]{2}{*}{1} & $\mathrm{~F}$ & 53 & II & $1 \mathrm{~A}$ & 1998 & No treatment & RNA not extractable \\
\hline & & & & $1 \mathrm{~B}$ & 2001 & No treatment & Group analysis-untreated \\
\hline \multirow[t]{2}{*}{2} & $\mathrm{~F}$ & 72 & I & $2 \mathrm{~A}$ & 1995 & No treatment & Group analysis-untreated \\
\hline & & & & $2 \mathrm{~B}$ & 2002 & Chlorambucil & Group analysis-treated \\
\hline \multirow[t]{2}{*}{3} & M & 60 & II & $3 \mathrm{~A}$ & 1993 & Chlorambucil & Group analysis-treated \\
\hline & & & & $3 \mathrm{~B}$ & 1995 & Cladribine & Not included in group analysis \\
\hline \multirow[t]{2}{*}{4} & $\mathrm{~F}$ & 68 & II & $4 \mathrm{~A}$ & 1995 & No treatment & Group analysis_-untreated \\
\hline & & & & $4 \mathrm{~B}$ & 1997 & No treatment & Not included in group analysis \\
\hline \multirow[t]{2}{*}{5} & $\mathrm{~F}$ & 51 & I & $5 \mathrm{~A}$ & 1996 & $\begin{array}{l}\text { Chlorambucil } \\
\text { VACOBP }\end{array}$ & Group analysis-treated \\
\hline & & & & $5 \mathrm{~B}$ & 1999 & $\begin{array}{l}\text { Cladribine } \\
\text { Fludarabine }\end{array}$ & Not included in group analysis \\
\hline \multirow[t]{2}{*}{6} & M & 53 & I & $6 \mathrm{~A}$ & 1997 & Chlorambucil & Group analysis-treated \\
\hline & & & & $6 \mathrm{~B}$ & 1997 & No treatment & Not included in group analysis \\
\hline
\end{tabular}

(b) Follicular lymphoma cases

\begin{tabular}{|c|c|c|c|c|c|c|c|c|}
\hline Patient & Gender & $\begin{array}{l}\text { Age at } \\
\text { diagnosis }\end{array}$ & $I P I$ & $\begin{array}{l}\text { Sample } \\
\text { label }\end{array}$ & $\begin{array}{l}\text { Year of } \\
\text { biopsy }\end{array}$ & Grade & $\begin{array}{l}\text { Treatment(s) } \\
\text { before biopsy }\end{array}$ & $\begin{array}{l}\text { Oligonucleotide microarray } \\
\text { analysis }\end{array}$ \\
\hline \multirow[t]{2}{*}{1} & \multirow[t]{2}{*}{$\mathrm{F}$} & \multirow[t]{2}{*}{46} & \multirow[t]{2}{*}{1} & $1 \mathrm{~A}$ & 2000 & 1 & No treatment & Group analysis-untreated \\
\hline & & & & $1 \mathrm{~B}$ & 2003 & 2 & $\begin{array}{l}\text { Chlorambucil } \\
\text { CHOP }+ \text { R }\end{array}$ & Group analysis-treated \\
\hline \multirow[t]{2}{*}{2} & \multirow[t]{2}{*}{$\mathrm{F}$} & \multirow[t]{2}{*}{63} & \multirow[t]{2}{*}{2} & $2 \mathrm{~A}$ & 2002 & 1 & No treatment & Group analysis-untreated \\
\hline & & & & $2 \mathrm{~B}$ & 2002 & NA & No treatment & $\begin{array}{l}\text { Not included in group } \\
\text { analysis }\end{array}$ \\
\hline \multirow[t]{2}{*}{3} & \multirow[t]{2}{*}{$\mathrm{F}$} & \multirow[t]{2}{*}{57} & \multirow[t]{2}{*}{0} & $3 \mathrm{~A}$ & 2002 & 1 & No treatment & Group analysis-untreated \\
\hline & & & & 3B & 2002 & NA & No treatment & $\begin{array}{l}\text { Not included in group } \\
\text { analysis }\end{array}$ \\
\hline \multirow[t]{2}{*}{4} & \multirow[t]{2}{*}{$\mathrm{F}$} & \multirow[t]{2}{*}{53} & \multirow[t]{2}{*}{0} & $4 \mathrm{~A}$ & 1999 & 1 & Chlorambucil & Group analysis-treated \\
\hline & & & & $4 \mathrm{~B}$ & 2000 & NA & No treatment & $\begin{array}{l}\text { Not included in group } \\
\text { analysis }\end{array}$ \\
\hline \multirow[t]{2}{*}{5} & \multirow[t]{2}{*}{$\mathrm{F}$} & \multirow[t]{2}{*}{54} & \multirow[t]{2}{*}{1} & $5 \mathrm{~A}$ & 1999 & 2 & No treatment & Group analysis-untreated \\
\hline & & & & $5 \mathrm{~B}$ & 2000 & NA & No treatment & $\begin{array}{l}\text { Not included in group } \\
\text { analysis }\end{array}$ \\
\hline \multirow[t]{2}{*}{6} & \multirow[t]{2}{*}{ M } & \multirow[t]{2}{*}{53} & \multirow[t]{2}{*}{0} & $6 \mathrm{~A}$ & 1997 & 2 & No treatment & Group analysis-untreated \\
\hline & & & & $6 \mathrm{~B}$ & 1999 & 2 & CHOP & Group analysis-treated \\
\hline \multirow[t]{2}{*}{7} & \multirow[t]{2}{*}{ M } & \multirow[t]{2}{*}{74} & \multirow[t]{2}{*}{2} & $7 \mathrm{~A}$ & 1997 & 2 & No treatment & Group analysis-untreated \\
\hline & & & & $7 \mathrm{~B}$ & 1998 & 2 & Chlorambucil & Group analysis-treated \\
\hline
\end{tabular}

VACOBP = etoposide, adriamycin, cyclophosphamide, vincristine, bleomycin and cisplatin; IPI = International Prognostic Index (out of a score of 5); $\mathrm{CHOP}=$ cyclophosphamide, adriamycin, vincristine, prednisone; $\mathrm{R}=$ rituximab; NA = not applicable.

treated included chlorambucil $(n=4)$, fludarabine $(n=4)$, chlorambucil followed by fludarabine $(n=1)$, and a combination of cyclophosphamide, vincristine, and prednisone $(n=1)$. The immunohistochemical method has been detailed elsewhere. $^{15}$ Briefly, after deparaffinization using xylene, the slides were subjected to antigen retrieval for $10 \mathrm{~min}$ using heated EDTA $(\mathrm{pH}=8.0)$ at $100^{\circ} \mathrm{C}$. The slides were subsequently incubated with the rabbit polyclonal anti-BIRC5/survivin antibodies at 1/100 dilution (Novus Biologicals Inc., Littleton, CO, USA) for $30 \mathrm{~min}$ at room temperature in a humidified chamber and then incubated with antirabbit Envision Plus (Dako, Mississauga, ON, Canada) for $30 \mathrm{~min}$. Color was developed with diaminobenzidine and counterstained with hematoxylin. For each case, a score of 0 (negative), 1 (weak staining), or 2 (strong staining) was assigned by two independent observers based on immunoreactivity in the majority of neoplastic lymphoid cells. Evaluation of immunostaining was performed without knowledge of the clinical history. The final score for each specimen represents the average of two readings from each of the two observers (MAK, RL). Cases with discrepancy in scoring were reviewed by both observers on a multiheaded microscope.

\section{Results}

\section{Clinical Characteristics of Patients Included in the Study}

We identified 12 frozen tissue samples from six chronic lymphocytic leukemia patients and 14 frozen tissue samples from seven follicular lymphoma patients, and details of these cases are summarized 
in Table 1. Subsequent review of the clinical information showed that two of six chronic lymphocytic leukemia patients had no chemotherapy at the time of both biopsies, three of six chronic lymphocytic leukemia patients received chemotherapy at the time of both biopsies, and one of six chronic lymphocytic leukemia patients had chemotherapy only at the time of the second biopsy. In the follicular lymphoma group, three of seven patients had no chemotherapy at the time of both biopsies, one of seven patients had chemotherapy at the time of both biopsy samples, and three of seven patients had chemotherapy only at the time of the second biopsy.

For the specimen pairs in which both samples were either treated or untreated (ie all chronic lymphocytic leukemia cases except case \#2 and all follicular lymphoma cases except cases \#1, 6 and 7), we did not identify any consistent changes in gene expression between the initial biopsies and subsequent biopsies using the criteria described in Materials and methods (ie $>2$-fold difference in gene expression with at least one of the two results $>0.2$ ). With the exception of patient \#1 in the chronic lymphocytic leukemia group, only the initial specimen from each pair was included for further statistical analysis in order to avoid using data from the same patient twice during group calculation. As no RNA was extractable from the first biopsy of patient \#1 in the chronic lymphocytic leukemia group, the second biopsy was used. Thus, among the initially identified 12 chronic lymphocytic leukemia specimens and 14 follicular lymphoma specimens, only seven samples from six chronic lymphocytic leukemia patients and 10 follicular lymphoma samples from seven patients were used for further statistical analysis for the remainder of this study (Table 1).

The age of the six chronic lymphocytic leukemia patients included for analysis ranged from 51 to 72 years (median age $=63$ years). There were two men and four women, all of these patients were in Rai I or II stage at the time of diagnosis. Three of seven samples were derived from previously untreated patients, and the remaining four samples were derived from patients exposed to chemotherapeutic agents, which were chlorambucil in all four cases. Pre- and postchemotherapy tumor samples derived from the same patient were available in one patient (patient \#2).

The age of the seven follicular lymphoma patients included in this study ranged from 53 to 74 years (median age $=54$ years), and there were two men and five women. Six of 10 samples were derived from tumors at the time of initial diagnosis. The remaining four samples were derived from tumors exposed to chemotherapeutic agents, with chlorambucil as the single agent in two cases, CHOP (cyclophosphamide, adriamycin, vincristine, prednisone) in one case, and chlorambucil followed by CHOP and rituximab in one case. Pre- and postchemotherapy tumor samples derived from the same patients were available in three patients (patient \#1, 6 and 7). The international prognostic index for all seven patients was between 0 and 2 .

\section{Apoptotic Gene Expression Profile between Chronic Lymphocytic Leukemia and Follicular Lymphoma}

Figure 1 illustrated the gene expression patterns of all samples from the six chronic lymphocytic leukemia patients and seven follicular lymphoma patients included in this study. The overall expression was strikingly similar among all cases, regardless of the diagnosis (chronic lymphocytic leukemia vs follicular lymphoma) and exposure to chemotherapy. Three genes (MCL1, TNFRSF1B and TNFRSF7) were highly expressed in the vast majority of the 17 samples; the average standardized expression levels for these three genes were $0.89,0.92,0.98$, respectively, comparable to that of housekeeping genes (set as 1.00). The standard deviations for these three genes were relatively small, being $0.11,0.11,0.03$, respectively.

In order to eliminate any potential confounding effects of chemotherapy-induced changes, we compared the group gene expression averages derived from three untreated chronic lymphocytic leukemia samples with those derived from six untreated follicular lymphoma samples. The untreated chronic lymphocytic leukemia group and follicular lymphoma group exhibited a strikingly similar pattern of gene expression among the 112 apoptotic genes (Pearson correlation coefficient $=0.94$ ). When only genes with a standardized expression level of $>0.2$ were examined, 26 genes were identified in chronic lymphocytic leukemia and 42 genes in follicular lymphoma; all except three of these 26 genes in chronic lymphocytic leukemia were represented in the list of the 42 highly expressed genes in follicular lymphoma. As illustrated in Table 2, for the 12 most highly expressed genes in the untreated chronic lymphocytic leukemia group, only two genes ( $A K T 1$ and $B C L 2$ ) were not included in the corresponding gene list for untreated follicular lymphoma. Conversely, of the 12 most highly expressed genes in the untreated follicular lymphoma group, only two genes (LTA and TP53) were not found in the corresponding gene list in the untreated chronic lymphocytic leukemia group. MCL1, TNFRSF1B and TNFRSF7 were highly expressed in both groups (Table 3 and illustrated in Figure 2), and the there was relatively little variability among cases for these three genes (the standard deviations were between 0.02 and 0.05 ). The less highly expressed genes had relatively more variability among cases, probably due to the fact that weaker signals are generally more prone to random technical errors and background variability.

While we observed significant similarities between previously untreated chronic lymphocytic leukemia and follicular lymphoma, we identified six genes that differentiate between the two lym- 


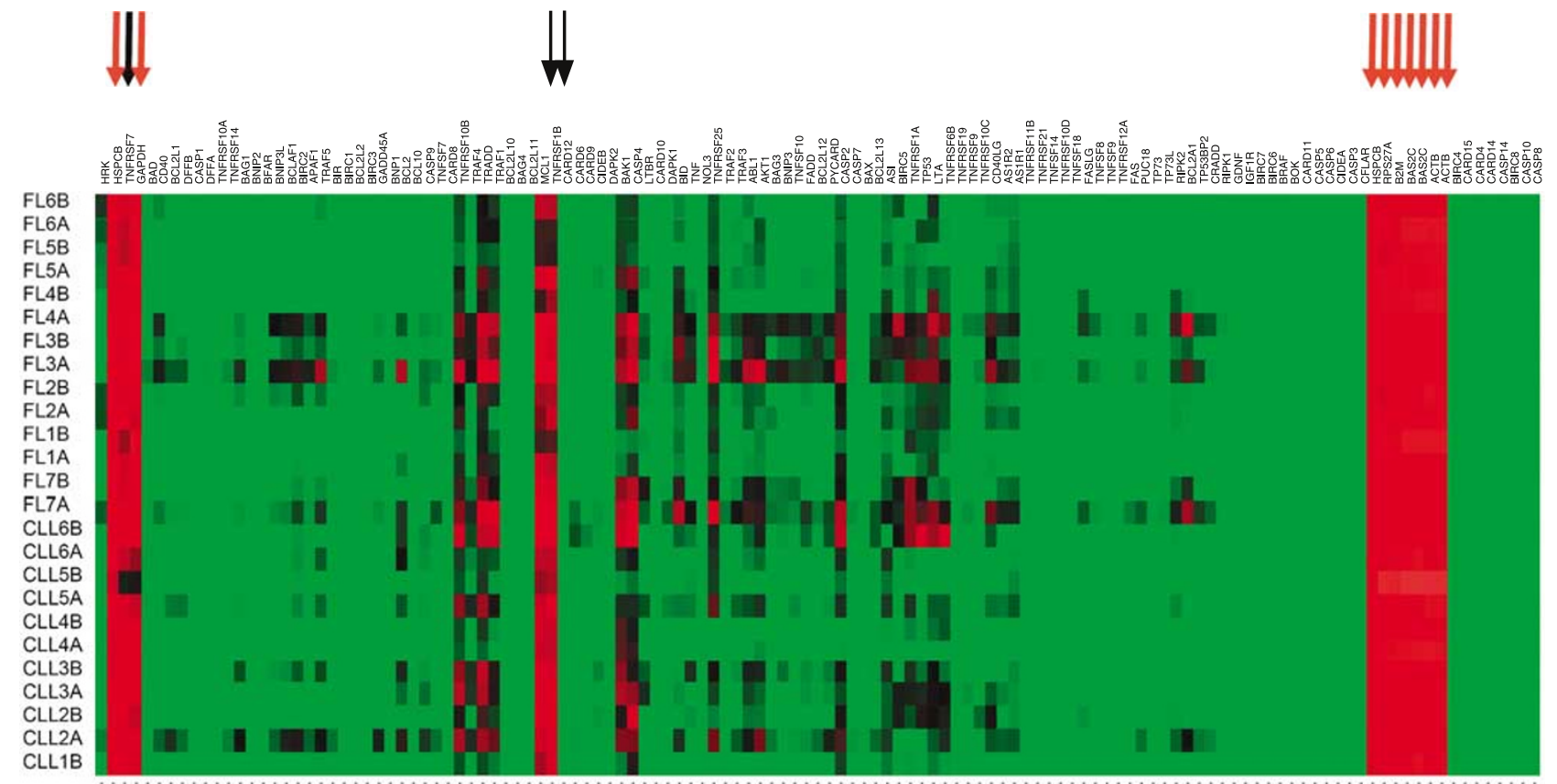

Figure 1 Clustogram analysis of chronic lymphocytic leukemia and follicular lymphoma. Bright red, black, and bright green represent high, average, and low levels of gene expression, respectively. The overall gene expression pattern was generally similar among all cases, regardless of the type of lymphoma and prior exposure to chemotherapy. Of the 112 apoptotic genes, MCL1, TNFRSF7, and TNFRSF1B were highly expressed in the vast majority of cases (black arrows), at a level comparable to that of housekeeping genes (red arrows)

Table 2 Comparison of apoptotic gene expression between untreated chronic lymphocytic leukemia and follicular lymphoma cases

\begin{tabular}{lcc}
\hline Genes & $\begin{array}{c}\text { Average standardized } \\
\text { gene expression }\end{array}$ & $\begin{array}{c}\text { Standard } \\
\text { deviation }\end{array}$ \\
\hline Untreated chronic lymphocytic leukemia $(n=3)$ & \\
TNFRSF7 & 0.98 & 0.02 \\
TNFRSF1B & 0.94 & 0.03 \\
MCL1 & 0.90 & 0.05 \\
CASP4 & 0.67 & 0.09 \\
BAK1 & 0.59 & 0.27 \\
TNFRSF10B & 0.53 & 0.28 \\
TRADD & 0.52 & 0.27 \\
CASP2 & 0.43 & 0.23 \\
TRAF1 & 0.40 & 0.28 \\
AKT1 & 0.37 & 0.34 \\
TNFRSF25 & 0.34 & 0.36 \\
BCL2 & 0.32 & 0.27 \\
Untreated follicular lymphoma & \\
TNFRSF7 & & \\
TNFRSF1B & 0.98 & 0.05 \\
MCL1 & 0.91 & 0.14 \\
TRADD & 0.89 & 0.14 \\
CASP4 & 0.72 & 0.21 \\
TNFRSF10B & 0.72 & 0.26 \\
TNFRSF25 & 0.62 & 0.21 \\
TRAF1 & 0.62 & 0.30 \\
BAK1 & 0.60 & 0.31 \\
CASP2 & 0.59 & 0.26 \\
LTA & 0.58 & 0.27 \\
TP53 & 0.52 & 0.21 \\
\hline
\end{tabular}

For each gene, the group average of the standardized expression level was calculated (maximum $=1.0$ ), along with the standard deviation. Only the 12 genes with the highest expression levels for each lymphoma are shown.
Table 3 Differentially expressed genes ( $>2$-fold) between untreated chronic lymphocytic leukemia and follicular lymphoma samples

\begin{tabular}{llc}
\hline Gene & Gene name & $\begin{array}{c}\text { Fold (follicular } \\
\text { lymphoma/chronic } \\
\text { lymphocytic leukemia) }\end{array}$ \\
\hline TP53 & Tumor protein p53 & 3.21 \\
TNF & Tumor necrosis factor & 2.54 \\
TNFRSF1A & Tumor necrosis factor & 2.47 \\
& receptor superfamily, & \\
BIRC5/ & member 1A & 2.36 \\
survivin & Baculoviral IAP repeat- & \\
CD40LG & Containing 5 (BIRC5) & 2.33 \\
& CD40 ligand (TNF & 2.07 \\
BID & superfamily, member 5) & \\
& BH3 interacting domain & \\
& death agonist & \\
\hline
\end{tabular}

phoma types, with at least a two-fold difference in expression and with one or both results in comparison being $>0.2$ in expression. These genes included TP53, TNF, TNFRSF1A, BIRC5/Survivin, CD4OLG and BID, all of which were expressed higher in the follicular lymphoma group than the chronic lymphocytic leukemia group (Table 3).

\section{Treatment-Related Differential Gene Expression in Chronic Lymphocytic Leukemia and Follicular Lymphoma}

In an attempt to identify differential gene expression that may be related to exposure to chemotherapy, we 
TNFRSF7

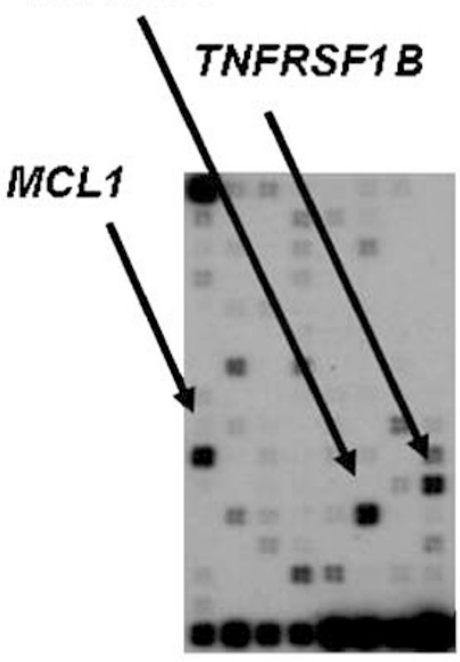

FL 1A

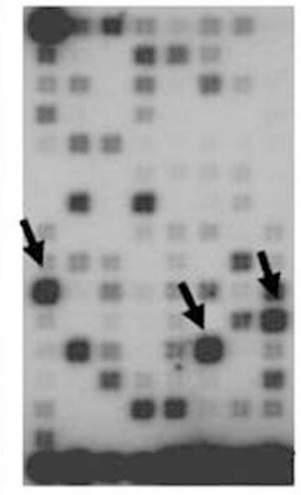

FL 3A

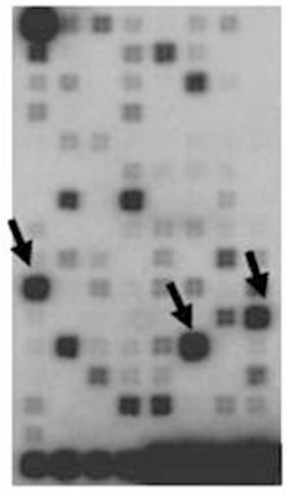

FL 7A

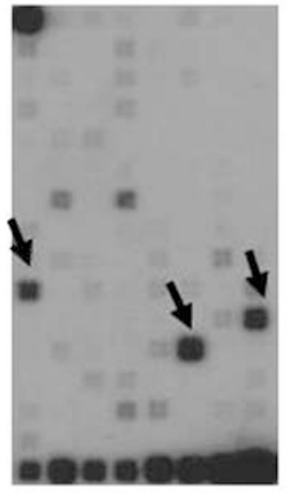

CLL 1B

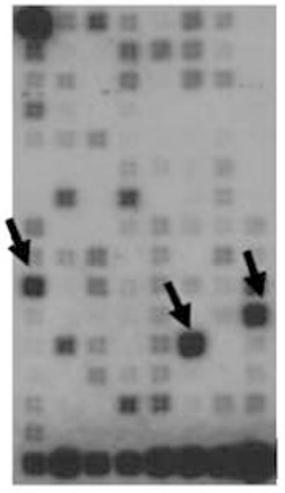

CLL 2A

Figure 2 Oligonucleotide microarrays of 2 previously untreated chronic lymphocytic leukemia and 3 previously untreated follicular lymphoma samples. The overall signal pattern was similar. The arrows highlight the 3 genes (MCL1, TNFRSF1B, and TNFRSF7) that were consistently and highly expressed regardless of the diagnosis (chronic lymphocytic leukemia vs follicular lymphoma) and history of prior exposure to treatments.

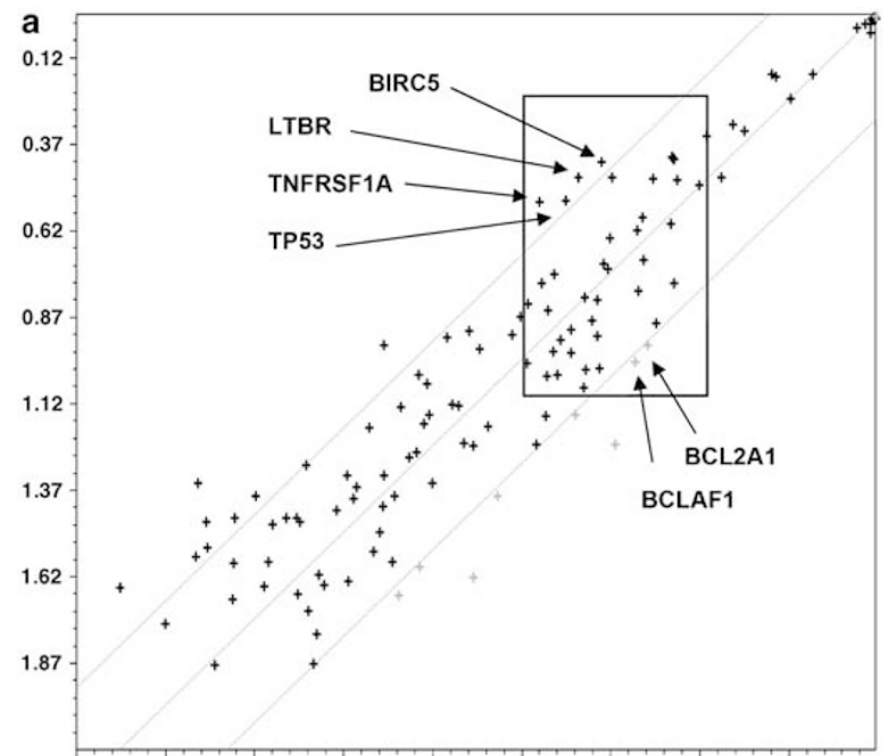

b

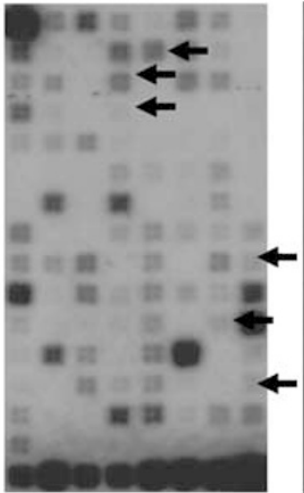

Before

Treatment

(CLL 2A)

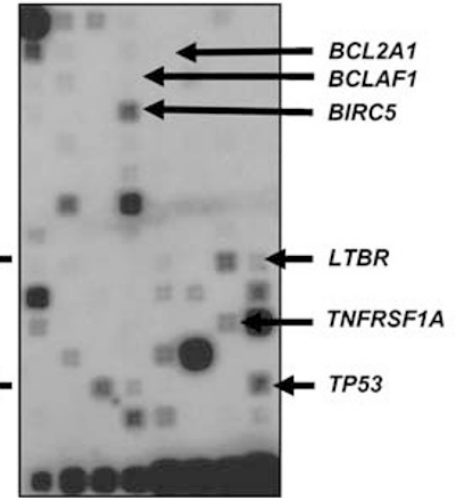

After

Chlorambucil

Treatment

(CLL 2B)

Figure 3 Chemotherapy-related differential gene expression in chronic lymphocytic leukemia. Correlating the apoptotic gene expression between untreated patients ( $x$ axis) and treated patients ( $y$ axis), the scatterplot group analysis (a) displays genes with greater than twofold as lying outside the parallel lines. Only the relatively highly expressed genes were examined in this study (boxed), and these genes include BIRC5/Survivin, LTBR, TNFRSF1A, and TP53 (upregulated), and BCL2A1 and BCLAF1 (downregulated). When this treatmentrelated differential gene expression derived from the group analysis was re-examined in an individual chronic lymphocytic leukemia patient with both a previously untreated specimen and a treated specimen (b), the changes in gene expression were highly consistent with the group analysis results.

compared the group gene expression averages derived from three untreated chronic lymphocytic leukemia samples with those derived from four chronic lymphocytic leukemia samples previously exposed to chemotherapy. As illustrated in Figure 3a, we identified six genes showing a $>2$-fold difference and being relatively highly expressed (ie
$>0.2$ ) in one or both results used for comparison. Specifically, BIRC5/Survivin, LTBR, TNFRSF1A, and TP53 were higher in the chemotherapy-treated group, and BCL2A1 and BCLAF1 were lower in the chemotherapy-treated group (summarized in Table 4). To further support these findings, we used the data from the single chronic lymphocytic 
Table 4 Differentially expressed genes ( $>2$-fold) between previously untreated and previously treated chronic lymphocytic leukemia samples

\begin{tabular}{llc}
\hline Gene & Gene name & $\begin{array}{c}\text { Fold (after } \\
\text { treatment/before } \\
\text { treatment) }\end{array}$ \\
\hline BIRC5/survivin & $\begin{array}{l}\text { Baculoviral IAP repeat- } \\
\text { containing 5 (BIRC5) }\end{array}$ & 2.56 \\
TP53 & Tumor protein p53 & 2.34 \\
TNFRSF1A & Tumor necrosis factor & 2.24 \\
& $\begin{array}{l}\text { receptor superfamily, } \\
\text { member 1A }\end{array}$ & \\
LTBR & Lymphotoxin $\beta$-receptor & 2.17 \\
& $\begin{array}{l}\text { (TNFR superfamily, } \\
\text { member 3) }\end{array}$ & \\
BCLAF1 & $\begin{array}{l}\text { BCL2-associated } \\
\text { transcription factor 1 }\end{array}$ & 0.49 \\
\hline & BCL2-related protein A1 & 0.48 \\
\hline
\end{tabular}

leukemia patient in which both pre- and postchemotherapy tumor samples were available (ie case \#2, Figure $3 \mathrm{~b}$ ). Five of the six genes identified, including BIRC5/Survivin, TP53, and TNFRSF1A (upregulated in the postchemotherapy sample), BCL2A1 and $B C L A F 1$ (downregulated in the postchemotherapy sample) were differentially expressed (ie $>2$-fold difference).

To ensure that these changes are related to chemotherapy and not simply related to disease progression over time, we examined if these six genes were modulated in two chronic lymphocytic leukemia patients (\#4 and \#6), in whom no chemotherapy was given to the patient at the time of both the first and second biopsy. We did not detect any significant changes in any of these six genes between the first and second biopsy samples in these two patients.

Similar analysis was performed for comparing the group gene expression averages derived from six untreated follicular lymphoma samples with those derived from four postchemotherapy samples. We did not detect any differentially expressed genes (ie $>2$-fold) that were also relatively highly expressed (ie $>0.2$ )

\section{Immunohistochemical Evaluation of Survivin Expression in Chronic Lymphocytic Leukemia Samples with or without Prior Exposure to Chemotherapy}

To validate the finding of survivin upregulation in the postchemotherapy chronic lymphocytic leukemia, compared to the pretreatment chronic lymphocytic leukemia, we performed immunohistochemical staining using an antisurvivin polyclonal antibody and 10 untreated and nine postchemotherapy chronic lymphocytic leukemia samples, all of which were randomly chosen. As shown in Table 5 two of eight untreated as opposed eight of nine postchemotherapy chronic lymphocytic leukemia samples were scored as positive for survivin $(P<0.006$,
Table 5 Expression of survivin in chronic lymphocytic leukemia samples with or without prior exposure to chemotherapy

\begin{tabular}{lccc}
\hline & $\begin{array}{c}\text { Cases with no prior } \\
\text { exposure to } \\
\text { chemotherapy }\end{array}$ & $\begin{array}{c}\text { Cases with prior } \\
\text { exposure to } \\
\text { chemotherapy }\end{array}$ & \\
\hline $\begin{array}{l}\text { Negative (0) or } \\
\text { weak (1+) survivin }\end{array}$ & 8 & 1 & 9 \\
$\begin{array}{l}\text { staining } \\
\text { Strong (2+) } \\
\text { survivin staining }\end{array}$ & 2 & 8 & 10 \\
Total & 10 & 9 & 19 \\
\hline
\end{tabular}

$P<0.006$ (Fisher's exact test)

Fisher's exact test). Figure 4 illustrated that the cellular localization of survivin staining was predominantly cytoplasmic, consistent with two other reports. ${ }^{16,17}$

\section{Discussion}

The pathogenesis of low-grade B-cell lymphoma is incompletely understood, but multiple defects in the apoptotic pathway are believed to play a significant role. By prolonging cell survival, these defects promote tumorigenesis, and may also contribute to chemotherapy resistance. Drug resistance poses a significant challenge for both chronic lymphocytic leukemia and follicular lymphoma patients, as they become more difficult to treat after relapse. ${ }^{4,18-22}$ Further understanding of the apoptotic pathways underlying the mechanisms for carcinogenesis and drug resistance may allow us to identify molecular targets for altering the natural history of these tumors.

In this study, using apoptotic pathway-specific oligonucleotide arrays, we evaluated the apoptotic gene expression pattern of chronic lymphocytic leukemia and follicular lymphoma. By analyzing only the previously untreated cases, we eliminated any potential confounding effects introduced by chemotherapeutic agents. We found a remarkable similarity between the apoptotic gene expression profiles of the untreated chronic lymphocytic leukemia group and the untreated follicular lymphoma group (Pearson correlation coefficient 0.94). The high degree of similarity in apoptotic gene expression suggests that these two types of low-grade B-cell lymphomas share common defects in the apoptotic pathway. Our findings are in keeping with those of another study using CNIO OncoChip (cDNA microarray containing 6386 genes), which also found significant homogeneity among lymphomas of small lymphoid cells, including chronic lymphocytic leukemia, follicular lymphoma, mantle cell lymphoma, and splenic marginal zone lymphoma. ${ }^{23}$ Our conclusion is also consistent with that of the only other study directly comparing apoptotic gene 

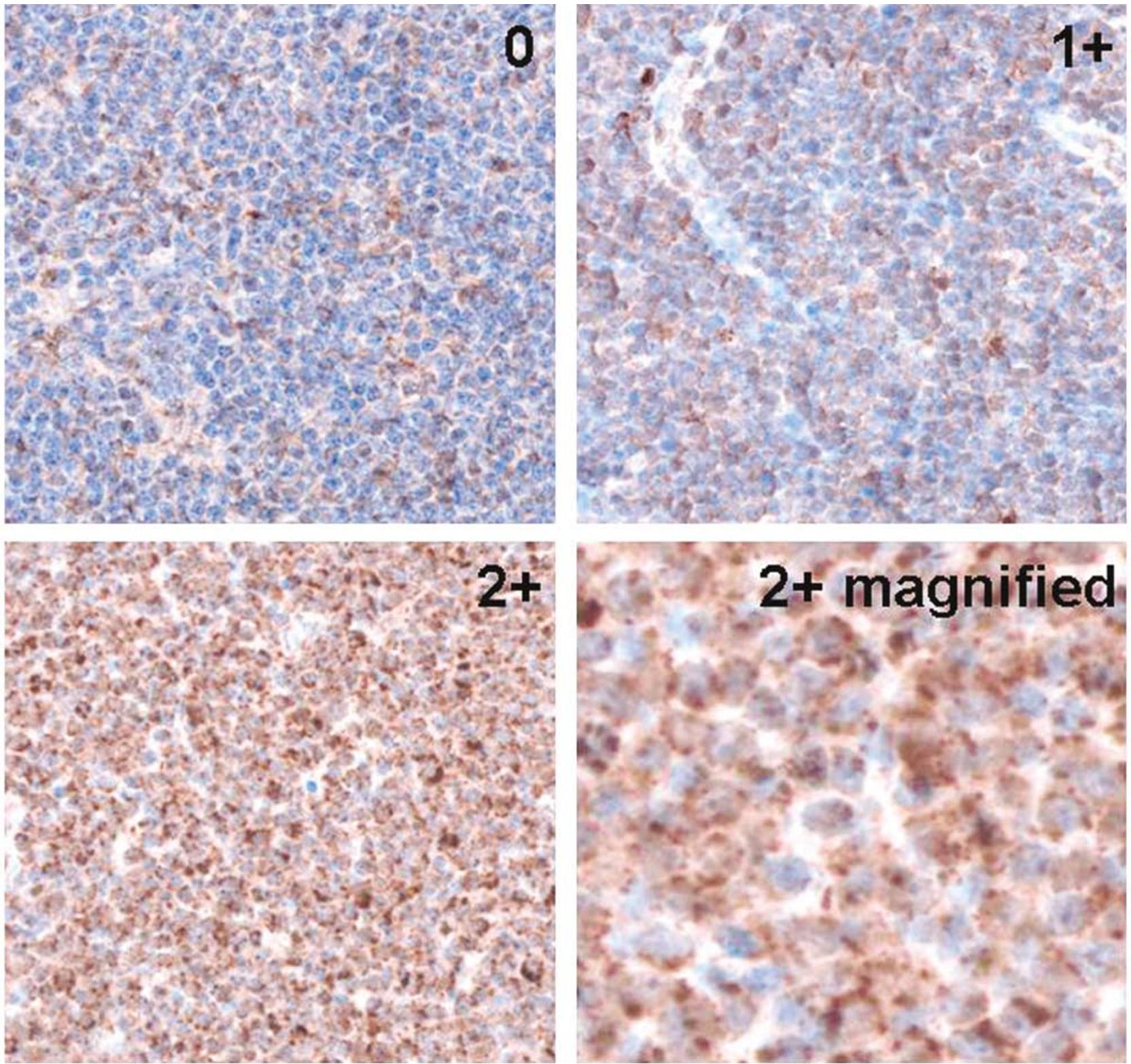

Figure 4 Immunohistochemical analysis of chronic lymphocytic leukemia samples with an antisurvivin antibody. Two untreated chronic lymphocytic leukemia samples with a score of $0+$ and $1+$, as well as a previously treated sample with a score of +2 are shown. As shown in the magnified view (right lower corner), staining was mainly confined to the cytoplasm.

expression between chronic lymphocytic leukemia and follicular lymphoma, which identified only 19 (out of a total of 13500 genes) sequences that exhibit a differential expression of $>4$-fold between chronic lymphocytic leukemia and follicular lymphoma, only one of which was an apoptotic gene (ie IL24). ${ }^{13}$ While our study did not identify IL24 as differentially expressed, this discrepancy could be explained by the use of different microarrays (genome-scale vs pathway-specific, which does not contain IL24). Thus, using different approaches, these two studies and our study have come to a similar conclusion regarding a common pattern of apoptotic gene expression between follicular lymphoma and chronic lymphocytic leukemia.
A small number of genes are consistently and highly expressed, regardless of the diagnosis (chronic lymphocytic leukemia $v s$ follicular lymphoma) or exposure to chemotherapy. These genes included MCL1, TNFRSF7, and TNFRSF1B, all of which have been reported to have antiapoptotic functions. MCL1 has been extensively studied and is a BCL2 family protein that has antiapoptotic function. ${ }^{10}$ It has been implicated in conferring resistance to chemotherapy in chronic lymphocytic leukemia, ${ }^{24-26}$ and overexpression of MCL1 promotes tumorigenesis in a transgenic mice model. ${ }^{27}$ High levels of MCL1 expression has been found in several types of malignant lymphoma, including anaplastic large cell lymphoma ${ }^{28}$ and mantle cell lymphoma. ${ }^{29}$ MCL1 was 
found to be low or absent in most cases of chronic lymphocytic leukemia and low or moderate in most cases of follicular lymphoma in one immunohistochemical study, ${ }^{30}$ but it was found to be variably expressed by chronic lymphocytic leukemia in another study using Western blot analysis. ${ }^{25}$ The difference between the results of these two studies and ours is probably related to the use of different detection methods; these two studies employed antibody-based assay (immunohistochemistry and Western blots) detecting protein expression, whereas ours used oligonucleotide arrays examining gene expression.

The other two genes, TNFRSF7 and TNFRSF1B, are both members of the TNF superfamily, although neither has been extensively studied. A recent metaanalysis of three microarray studies comparing gene expression between chronic lymphocytic leukemia and normal B cells also found that TNFRSF7 and TNFRSF1B were overexpressed in chronic lymphocytic leukemia, ${ }^{31}$ although similar findings have not been reported for follicular lymphoma. TNFRSF7 interacts with CD40 to inhibit apoptosis in B cells. ${ }^{32}$ TNFRSF1B has been found to be involved in both proapoptotic and antiapoptotic signaling. ${ }^{33}$

Despite the overall similarities between chronic lymphocytic leukemia and follicular lymphoma, we detected differences between samples derived from untreated chronic lymphocytic leukemia and follicular lymphoma. The six genes identified were $B I D$, BIRC5/Survivin, CD4OLG, TNF, TNFRSF1A, and TP53. All of which had greater than two-fold difference in expression between the two groups, and were more highly expressed in follicular lymphoma relative to chronic lymphocytic leukemia. Using real-time quantitative polymerase chain reaction, Graaf et $a l^{34}$ analyzed the expression patterns of 10 apoptosisregulating genes in 137 samples from various B- and T-cell lymphoid malignancies, and identified three members of the inhibitors of apoptosis family, including BIRC5/Survivin, as the most informative genes to distinguish between different lymphomas. Specifically, the expression of BIRC5/Survivin in follicular lymphoma was much higher than in chronic lymphocytic leukemia, consistent with our results.

In addition to being differentially expressed between chronic lymphocytic leukemia and follicular lymphoma, BIRC5/Survivin was also one of the four genes in which a greater than two-fold increase was identified when we compared the previously untreated and treated chronic lymphocytic leukemia (Table 5). Consistent with our observation, one recent in vitro study using chronic lymphocytic leukemia derived cell lines described an elevation of BIRC5/Survivin levels after cladribine treatment. ${ }^{35}$ BIRC5/Survivin has also been identified as one of the top four transcripts among 3.5 million human transcriptomes uniformly upregulated in cancer tissues but not in normal tissues. ${ }^{36}$ While BIRC5/ Survivin has been reported to be strongly expressed in chronic lymphocytic leukemia bone marrow by real-time reverse transcriptase polymerase chain reaction and immunohistochemistry, ${ }^{16}$ Sugahara et $a l^{37}$ employed real-time reverse transcriptase polymerase chain reaction and found that BIRC5/ Survivin was downregulated in most cases of chronic lymphocytic leukemia, supporting the results of a recent microarray study. ${ }^{23}$ In addition, Granziero et $a l^{16}$ reported that survivin was detected only in the pseudofollicules of chronic lymphocytic leukemia lymph nodes through immunohistochemistry. This inconsistency in BIRC5/Survivin levels may be explained by the different techniques and specimens used. Survivin controls apoptosis and participates in cell cycle progression ${ }^{38}$ regulating the chronic lymphocytic leukemia proliferation pool interfacing apoptosis in lymphoid organs. ${ }^{17}$ Furthermore, survivin has been reported to confer drug resistance in a few human malignancies, ${ }^{39}$ including taxol/platinum-based regimens in ovarian cancer ${ }^{40}$ and flutamide in prostate cancer. ${ }^{41}$ In addition to blocking programmed cell death, survivin may confer resistance through association with microtubule and mitotic spindle function. Our current study adds another dimension to this molecule as potentially responsible for treatment resistance in chronic lymphocytic leukemia.

Our study highlights the advantage of using pathway-specific arrays to examine gene expression of specific pathways in greater depth. The Oligo GEArrays employed in this study are able to detect targets at the $10 \mathrm{fM}$ range and at a spiking ratio of 1:300 000, a sensitivity that is comparable or better than other commercial microarrays (eg Affymetrix GeneChips). This makes it an excellent tool for studying low abundance transcripts. Another advantage is that of the relative simplicity of data analysis, since the analysis focuses on a much smaller number of biologically related genes.

By focusing only on the genes that are highly expressed, many of the biologically significant, yet lesser-expressed genes may not be captured in this study. However, it has been reported in microarrays that background noise makes it difficult to accurately quantify genes with low expression. ${ }^{42}$ In this study, we did not duplicate the microarray analysis for each sample, partly due to cost restrains. Indeed, this practice is not uncommon in studies using group analysis. ${ }^{23,31}$ We recognize that gene expression microarrays provide in vitro data primarily for generation of hypothesis. Thus, we have validated the upregulation of survivin in postchemotherapy chronic lymphocytic leukemia tumor samples with an in vivo method, immunohistochemistry.

To conclude, we report that the profile of apoptotic gene expression is strikingly similar among and between chronic lymphocytic leukemia and follicular lymphoma, strongly suggesting a common fundamental defect in the apoptotic pathway in these two types of lymphoma. We have also identified upregulation of potentially important antiapoptotic genes, including BIRC5/Survivin, in postchemo- 
therapy chronic lymphocytic leukemia cases, suggesting that these molecules may contribute to chemotherapy resistance.

\section{Acknowledgements}

This study is partly supported by research grants from the Alberta Cancer Board and the National Cancer Institute of Canada to RL. We would like to thank Mr Winson Wong for technical support.

\section{References}

1 Byrd JC, Stilgenbauer S, Flinn IW. Chronic lymphocytic leukemia. Hematology 2004;1:163-183.

2 Chiorazzi N, Rai KR, Ferrarini M. Chronic lymphocytic leukemia. N Engl J Med 2005;352:804-815.

3 Solal-Celigny P. Prognosis of follicular lymphomas. Clin Lymphoma 2005;6:21-25.

4 Gandhi MK, Marcus RE. Follicular lymphoma: time for a re-think? Blood Rev 2005;19:165-178.

5 Hiddemann W, Buske C, Dreyling M, et al. Treatment strategies in follicular lymphomas: current status and future perspectives. J Clin Oncol 2005;23:6394-6399.

6 Kokhaei P, Palma M, Mellstedt $\mathrm{H}$, et al. Biology and treatment of chronic lymphocytic leukemia. Ann Oncol 2005;16(Supplement ii):113-123.

7 Tsujimoto Y, Cossman J, Jaffe E, et al. Involvement of the bcl-2 gene in human follicular lymphoma. Science 1985;228:1440-1443.

8 McDonnell TJ, Deane N, Platt FM, et al. bcl-2-immunoglobulin transgenic mice demonstrate extended B cell survival and follicular lymphoproliferation. Cell 1989; 57:79-88.

9 Husson H, Carideo EG, Neuberg D, et al. Gene expression profiling of follicular lymphoma and normal germinal center B cells using cDNA arrays. Blood 2002; 99:282-289.

10 Packham G, Stevenson FK. Bodyguards and assassins: Bcl-2 family proteins and apoptosis control in chronic lymphocytic leukaemia. Immunology 2005;114: 441-449.

11 Klein U, Tu Y, Stolovitzky GA, et al. Gene expression profiling of $\mathrm{B}$ cell chronic lymphocytic leukemia reveals a homogeneous phenotype related to memory B cells. J Exp Med 2001;194:1625-1638.

12 Rosenwald A, Alizadeh AA, Widhopf G, et al. Relation of gene expression phenotype to immunoglobulin mutation genotype in B cell chronic lymphocytic leukemia. J Exp Med 2001;194:1639-1647.

13 Schmechel SC, LeVasseur RJ, Yang KH, et al. Identification of genes whose expression patterns differ in benign lymphoid tissue and follicular, mantle cell, and small lymphocytic lymphoma. Leukemia 2004;18:841-855.

14 Jablonska E, Kiersnowska-Rogowska B, Rogowski F, et al. TNF family molecules in the serum of patients with B-cell chronic lymphocytic leukemia (B-CLL). Leuk Lymphoma 2005;46:1307-1312.

15 Hui D, Reiman T, Hanson J, et al. Immunohistochemical detection of cdc2 is useful in predicting survival in patients with mantle cell lymphoma. Mod Pathol 2005;18:1223-1231.

16 Nakagawa Y, Yamaguchi S, Hasegawa $\mathrm{M}$, et al. Differential expression of survivin in bone marrow cells from patients with acute lymphocytic leukemia and chronic lymphocytic leukemia. Leuk Res 2004;28: 487-494.

17 Granziero L, Ghia P, Circosta P, et al. Survivin is expressed on CD40 stimulation and interfaces proliferation and apoptosis in B-cell chronic lymphocytic leukemia. Blood 2001;97:2777-2783.

18 Johnson PW, Rohatiner AZ, Whelan JS, et al. Patterns of survival in patients with recurrent follicular lymphoma: a 20-year study from a single center. J Clin Oncol 1995;13:140-147.

19 Tallman MS, Hakimian D, Zanzig C, et al. Cladribine in the treatment of relapsed or refractory chronic lymphocytic leukemia. J Clin Oncol 1995;13:983-988.

20 Summerfield GP, Taylor PR, Mounter PJ, et al. High-dose chlorambucil for the treatment of chronic lymphocytic leukaemia and low-grade non-Hodgkin's lymphoma. Br J Haematol 2002;116:781-786.

21 Kimby E, Brandt L, Nygren P, et al. A systematic overview of chemotherapy effects in B-cell chronic lymphocytic leukaemia. Acta Oncol 2001;40:224-230.

22 Panasci L, Paiement JP, Christodoulopoulos G, et al. Chlorambucil drug resistance in chronic lymphocytic leukemia: the emerging role of DNA repair. Clin Cancer Res 2001;7:454-461.

23 Tracey L, Perez-Rosado A, Artiga MJ, et al. Expression of the NF-kappaB targets BCL2 and BIRC5/Survivin characterizes small B-cell and aggressive B-cell lymphomas, respectively. J Pathol 2005;206:123-134.

24 Kitada S, Andersen J, Akar S, et al. Expression of apoptosis-regulating proteins in chronic lymphocytic leukemia: correlations with In vitro and In vivo chemoresponses. Blood 1998;91:3379-3389.

25 Saxena A, Viswanathan S, Moshynska O, et al. Mcl-1 and Bcl-2/Bax ratio are associated with treatment response but not with Rai stage in B-cell chronic lymphocytic leukemia. Am J Hematol 2004;75: 22-33.

26 Johnston JB, Paul JT, Neufeld NJ, et al. Role of myeloid cell factor-1 (Mcl-1) in chronic lymphocytic leukemia. Leuk Lymphoma 2004;45:2017-2027.

27 Zhou P, Qian L, Bieszczad CK, et al. Mcl-1 in transgenic mice promotes survival in a spectrum of hematopoietic cell types and immortalization in the myeloid lineage. Blood 1998;92:3226-3239.

28 Rassidakis GZ, Lai R, McDonnell TJ, et al. Overexpression of Mcl-1 in anaplastic large cell lymphoma cell lines and tumors. Am J Pathol 2002;160:23092310.

29 Khoury JD, Medeiros LJ, Rassidakis GZ, et al. Expression of Mcl-1 in mantle cell lymphoma is associated with high-grade morphology, a high proliferative state, and p53 overexpression. J Pathol 2003;199:90-97.

30 Agarwal B, Naresh KN. Bcl-2 family of proteins in indolent B-cell non-Hodgkin's lymphoma: study of 116 cases. Am J Hematol 2002;70:278-282.

31 Wang J, Coombes KR, Highsmith WE, et al. Differences in gene expression between B-cell chronic lymphocytic leukemia and normal B cells: a meta-analysis of three microarray studies. Bioinformatics 2004;20: 3166-3178.

32 Hase H, Kanno Y, Kojima H, et al. CD27 and CD40 inhibit p53-independent mitochondrial pathways in apoptosis of B cells induced by B cell receptor ligation. J Biol Chem 2002;277:46950-46958.

33 Depuydt B, van Loo G, Vandenabeele P, et al. Induction of apoptosis by TNF receptor 2 in a T-cell hybridoma is 
FADD dependent and blocked by caspase-8 inhibitors. J Cell Sci 2005;118:497-504.

34 Graaf AO, Han van Krieken J, Tonnissen E, et al. Expression of C-IAP1, C-IAP2 and SURVIVIN discriminates different types of lymphoid malignancies. Br J Haematol 2005;130:852-859.

35 Wall NR, Beck FW, Al-Katib AM, et al. Treatmentinduced expression of anti-apoptotic proteins in WSU-CLL, a human chronic lymphocytic leukemia cell line. J Drug Target 2001;9:329-339.

36 Altieri DC, Marchisio PC. Survivin apoptosis: an interloper between cell death and cell proliferation in cancer. Lab Invest 1999;79:1327-1333.

37 Sugahara K, Uemura A, Harasawa H, et al. Clinical relevance of survivin as a biomarker in neoplasms, especially in adult T-cell leukemias and acute leukemias. Int J Hematol 2004;80:52-58.
38 Reed JC. Molecular biology of chronic lymphocytic leukemia. Semin Oncol 1998;25:11-18.

39 Zangemeister-Wittke U, Simon HU. An IAP in action: the multiple roles of survivin in differentiation, immunity and malignancy. Cell Cycle 2004;3:11211123.

40 Zaffaroni N, Pennati M, Colella G, et al. Expression of the anti-apoptotic gene survivin correlates with taxol resistance in human ovarian cancer. Cell Mol Life Sci 2002;59:1406-1412.

41 Zhang M, Latham DE, Delaney MA, et al. Survivin mediates resistance to antiandrogen therapy in prostate cancer. Oncogene 2005;24:2474-2482.

42 Coombes KR, Highsmith WE, Krogmann TA, et al. Identifying and quantifying sources of variation in microarray data using high-density cDNA membrane arrays. J Comput Biol 2002;9:655-669. 